\title{
La venganza de Medusa: Cadalso y Rossetti ante la otra poética de la cabellera femenina
}

\author{
Ana Elena GoNZÁLEZ TREVIÑo \\ Universidad Nacional Autónoma de México
}

Even so much life hath the poor tress of hair Which, stored apart, is all love hath to show For heart-beats and for fire-heats long ago; Even so much life endures unknown, even where, 'Mid change the changeless night environeth, Lies all that golden hair undimmed in death.

'Life-in-Love', Dante Gabriel Rossetti

En la edición de 1822 de las Noches lúgubres de José Cadalso (1741-1782) apareció un documento fechado en 1791 y firmado con las iniciales M. A., bajo el título de Carta de un amigo de Cadalso sobre la exhumación clandestina del cadáver de la actriz María Ignacia Ibáñez. La carta alude a un notorio suceso ocurrido en la vida de Cadalso cuando estaba al servicio del conde de Aranda en Madrid en 1771. Se cuenta que María Ignacia Ibáñez, famosa actriz cómica, había cautivado y correspondido los amores de un Cadalso que acababa de volver tras seis meses de destierro y que se encontraba a la sazón "desnudo, pobre y desgraciado" (Cadalso: 16). Cadalso siempre le agradeció este gesto de generosidad, aun cuando socialmente la relación fuera motivo de escándalo, pues Cadalso, caballero de la Orden de Santiago, no debía rebajarse a los amores de una simple actriz. María Ignacia fue la musa e inspiración de Cadalso, sí, pero también su muñeca, su títere. Le escribió papeles dramáticos, y la alabó en sus poemas bajo el pastoril apelativo de "Filis". La relación duró sólo unos cuantos meses debido a que ella contrajo tifus y murió ese abril a los veinticinco años.

Las Noches se publicaron por primera vez por entregas en el Correo de Madrid (o de los ciegos) entre diciembre de 1789 y enero de 1790, siete años después de la muerte de Cadalso (aunque recientemente Nigel Glendinning dio a conocer un manuscrito de la Biblioteca Británica fechado hacia 1775) (Cadalso: 45 y 65-66). Cabe mencionar que en la famosa Carta LXVII de las 
Cartas marruecas, Cadalso, en voz de su alter ego Nuño, escribió: "Si el cielo de Madrid no fuese tan claro y hermoso y se convirtiese en triste, opaco y caliginoso como el de Londres... me atrevería yo a publicar las Noches lúgubres que he compuesto a la muerte de un amigo mío, por el estilo de las que escribió el doctor Young. La impresión sería en papel negro con letras amarillas..." (241). Terminó de escribir las Cartas marruecas en 1774 (si bien la censura tampoco permitió su publicación sino hasta 1789). La alusión a Young enlaza a Cadalso con una corriente específica. El poeta inglés publicó sus Night Thoughts entre 1742 y 1745 , con éxito inmediato en todos sentidos. Sus poemas son reflexiones sobre la muerte derivadas de experiencias reales, pues Young había perdido a su mujer, a su hija y a su yerno. Tuvo mucha influencia en España como parte de la moda sentimental del panteón que ahora asociamos con el prerromanticismo. La idea de incluir la Carta de un amigo de Cadalso... en la edición de 1822 sólo buscaba explotar comercialmente el lado más morboso de esta moda, insinuando con poca discreción que los sucesos relatados en las Noches también estaban basados en una experiencia real. ${ }^{1}$

La Carta cuenta que la enfermedad de María Ignacia hizo que "al tercer día de cama expirase en los brazos de su amante", y que Cadalso quedó tan afectado que "casi terminó en demencia". No se quería apartar de la tumba de su amada y "últimamente paró su violento dolor en la extravagancia de desenterrar el cadáver". Afortunadamente el conde de Aranda había enviado a unos espías para vigilarlo, y logró impedir la exhumación. Cadalso supuestamente compuso las Noches para purgar la experiencia, pero una vez "disipada la melancolía", fue incapaz de proseguir y la obra quedó inconclusa. Aun cuando esta misma carta afirma más adelante que "aquella obra era sólo hija de su sentimiento", y que no existe ninguna prueba válida de la veracidad de los hechos, la leyenda es tan atractiva que forma ya parte del mito cadalsiano (Cadalso: 46).

La imaginación romántica, en su faceta más mórbida, interpretaba el "amor constante más allá de la muerte" como un amor por el cuerpo más allá de la tumba. Aunque la cautelosa advertencia barroca en contra de la vanitas, representada por el memento mori de la calavera, se regodeaba en los detalles grotescos de la putrefacción, aquí se experimenta una fascinación casi infantil por el espectáculo de la corrupción de la carne y sobre todo por el lenguaje que se usa para describirla. En las Noches, Lorenzo, el enterrador coludido con el triste Tediato para profanar la tumba, exclama:

\footnotetext{
' Aunque Cadalso menciona explícitamente a Young, se han sembrado dudas sobre su influencia directa. Ni siquiera es seguro que Cadalso haya leído Night Thoughts en su totalidad. Ver John Dowling, "Las Noches lúgubres de Cadalso y la juventud romántica del Ochocientos”, en www.cervantesvirtual.com
} 
He enterrado por mis manos tiernos niños, delicias de sus mayores; mozos robustos, descanso de sus padres ancianos; doncellas hermosas, y envidiadas de las que quedaban vivas; hombres en lo fuerte de su edad, y colocados en altos empleos; viejos venerables, apoyos del Estado... Nunca temblé. Puse sus cadáveres entre otros muchos ya corruptos, rasgué sus vestiduras en busca de alguna alhaja de valor; apisoné con fuerza y sin asco sus fríos miembros, rompiles las cabezas y huesos; cubrilos de polvo, ceniza, gusanos y podre, sin que mi corazón palpitase..., y ahora, al pisar estos umbrales, me caigo..., me avergüenzo de mi flaqueza: no la refieras a mis compañeros. ¡Si lo supieran harian mofa de mi cobardía! (313). ${ }^{2}$

El horror de Lorenzo no es tan extraño como él cree. La cotidianidad de la muerte para el sepulturero se explica por el desapego con que ha aprendido a manipular los cadáveres en una fosa común emblemática por la que desfila toda la gama del género humano. Esta frialdad adquirida no lo ha vuelto inmune, sin embargo, a todo cuanto puede ocurrir en un cementerio. Cuando Tediato propone el desenterramiento, Lorenzo le pregunta si busca el cadáver de algún amigo o robar "las alhajas del templo, que se guardan en algún soterráneo, cuya puerta se te figura ser la losa que empiezo a levantar" (Cadalso: 325). Queda claro que su horror tampoco procede de que ahora Tediato le haya pedido invertir el rito ancestral del entierro, usando pico y pala no para cavar la fosa sino para profanar la tumba y desenterrar un cuerpo.

Lorenzo no puede levantar solo el peso de la losa sepulcral, y pide ayuda a Tediato, quien, podría decirse, debe cometer la profanación con sus propias manos. Cuando por fin logran arrastrar la piedra, les asalta una peste insoportable que incita a Lorenzo a salir huyendo, pero Tediato se lo impide. Apenas han abierto una ranura, y ya empiezan a desbordarse los gusanos que ahora cohabitan con la amada:

¡Ay, qué veo! Todo mi pie derecho está cubierto de [gusanos]. ¡Cuánta miseria me anuncian! En éstos, iay!, ¡en éstos se ha convertido tu carne! ¡De tus hermosos ojos se han engendrado estos vivientes asquerosos! ¡Tu pelo, que en lo fuerte de mi pasión llamé mil veces no sólo más rubio, sino más precioso que el oro, ha producido esta podre! ¡Tus blancas manos, tus labios amorosos se han vuelto materia y corrupción! ¡En qué estado estarán las tristes reliquias de tu cadáver! iA qué sentido no ofenderá la misma que fue el hechizo de todos ellos! (326).

${ }^{2}$ Este pasaje ha sido comparado con uno de fray Luis de Granada, Libro de oración I.ix.20. 
Lo que aquí se presencia es una inversión directa del blasón petrarquista del siglo anterior. Es una enumeración de partes del cuerpo femenino -ojos, pelo, manos, labios - antes deseado y lejano, y ahora repulsivo y demasiado cercano. Es digna de resaltarse, para los fines de este ensayo, la mención del cabello y su participación casi activa, junto con los ojos, para engendrar gusanos, que, aunados a la peste y la podredumbre, constituyen la nueva aura del cuerpo amado, una especie de prolongación de dicho cuerpo, que amenaza y agrede al osado pretendiente. La movilidad desbordante de los gusanos, así como la forma alargada de éstos, es una parodia funesta de la exuberancia del cabello de la mujer viva, y apunta ya a la imagen gorgónica de la mujer con cabellera de serpientes que deja petrificados a quienes se atreven a mirarla de frente. Más aún, esta lista de partes es lo que finalmente le revela a Lorenzo la verdadera causa de su horror primero. Las negras motivaciones de Tediato, el amante dolido, delatan una necrofilia profundamente irracional, cuyo carácter aberrante hace que sólo en la oscuridad nocturna pueda buscar satisfacción.

La Primera Noche concluye con una explicación un tanto forzada de Tediato, en la que asegura que su intención es sacar el cuerpo de la amada para llevarlo consigo y así "expirando incendiaré mi domicilio, y tú y yo nos volveremos ceniza en medio de las de la casa". Pero el hecho es que Lorenzo y Tediato jamás llevan a cabo la exhumación. Cadalso, a final de cuentas, únicamente quería experimentar con la escena del encuentro nocturno en el cementerio, la insinuación del amor contra natura y la imaginería convencional de la desintegración.

Cadalso no está solo en la galería de poetas desenterradores. Otro caso célebre es el del poeta y pintor prerrafaelista inglés de ascendencia italiana, Dante Gabriel Rossetti (1828-1882). Estaba casado con Elizabeth Siddal, quien posara para él y para muchos de los miembros de la Hermandad Prerrafaelista que supuestamente buscaba volver a la sencillez del arte anterior a Rafael. Shakespeare, el medievo, Italia y las expresiones artísticas católicas resultaban de gran interés para este grupo de poetas y pintores. Lizzie, como se conocía a la esposa de Rossetti, encarnaba el ideal de la mujer virginal y etérea, de tez transparente y undosa cabellera. Uno de los cuadros más conocidos para los que posó es la Ofelia de sir John Everett Millais (1829-1896). En él, la suicida aparece flotando en el río con las manos todavía repartiendo las flores alucinantes de su escena de locura. Para lograr el escalofriante realismo de la obra, Millais hizo que Lizzie posara tendida en una bañera llena de agua mal calentada por una fila de velas. Se cuenta que en una sesión las velas se apagaron sin que Millais se diera cuenta, y la modelo enfermó gravemente. Rossetti le fue infiel estando ella enferma, y se dice que el remordimiento lo acompañó el resto de su vida (Hawksley: 46). 
Lizzie murió de una sobredosis de láudano en 1862, a los treinta y tres años, sólo dos años después de haberse casado. Rossetti, en un gesto de romanticismo y contrición, quiso enterrar con ella el cuaderno donde había escrito todos sus poemas. Acomodó el volumen cerca de los labios de la muerta y lo envolvió con su larga cabellera rubia. Rossetti declaró junto a la tumba que esos poemas los había escrito sólo para ella, y que ella los custodiaría por toda la eternidad. Falsa generosidad. Siete años después Rossetti lamentó haber renunciado a la poesía, y quiso recobrar el manuscrito que según él era la única colección perfecta de sus mejores poemas. Hizo las gestiones correspondientes en el Cementerio de Highgate, en Londres, y una noche, a la luz de una hoguera enorme que se encendió, según algunos, para "prevenir infecciones", se desenterró y abrió el ataúd de Lizzie. Para horror de Rossetti, la dorada cabellera de su difunta esposa había seguido creciendo hasta desbordarse de la caja. El manuscrito se extrajo del ataúd. Un año después, en 1870 , se publicaron los poemas y fueron muy bien recibidos. Hasta hoy se consideran un monumento al amor conyugal. El incidente, no obstante, le afectó tanto a Rossetti, que en su testamento estipuló que quería ser incinerado, y que por ningún motivo se le enterrara junto a Lizzie (Hendrickson: 222). ${ }^{3}$

Aunque todos los prerrafaelistas estaban hasta cierto punto obsesionados por el cabello femenino, resulta irónico que Rossetti haya escrito un soneto a una de sus amantes, Fanny Cornforth (que además era su criada), en el que figura un joven amante víctima de la red de su cabellera malévola. La ironía se duplica al ver que dicho soneto fue escrito antes de la exhumación de Lizzie. Es un soneto sobre Lilith, la primera mujer de Adán, y afirma elogiosamente que "her enchanted hair was the first gold" (v. 4). Lilith aparece como una especie de araña que teje trampas para los hombres con su cabello:

[She] Draws men to match the bright web she can weave Till heart and body and life are in its hold. (vv. 7-8)

Así, aunque más adelante se mencionan sus ojos, su fragancia y sus besos, el arma mortifera resulta ser nuevamente el cabello, y, en una imagen de gusto bastante cuestionable, acaba por "estrangular" el corazón de su amado hechizado.

\footnotetext{
${ }^{3}$ Se recomienda ampliamente consultar The Dante Gabriel Rossetti Hypermedia Archive. La Biblioteca Británica posee un manuscrito virtualmente idéntico al enterrado con Elizabeth Siddal. Además hay colecciones de manuscritos relacionados con la familia Rossetti en la Biblioteca Bodleiana de Oxford, el Museo Fitzwilliam y la importante colección Troxell de la Universidad de Princeton, Nueva Jersey.
} 
Lo! As that youth's eyes burned at thine, so went

Thy spell through him, and left his straight neck bent

And round his heart one strangling golden hair. (vv. 12-14)

La anécdota podria interpretarse simplemente como un ejemplo más de excentricidad inglesa sin mayores consecuencias para el arte. Sin embargo, tanto la historia de Cadalso como la de Rossetti son más que meras curiosidades literarias. El relato de la amada muerta, enterrada y desenterrada, los detalles de los gusanos y el cabello, representan una fantasía repetida a menudo en la literatura y el folclor. Para comprender su significado conviene recordar un retrato póstumo de Lizzie pintado por Rossetti y titulado Beata Beatrix, que se convirtió en el símbolo de su amor imposible, emulando el amor de Dante por Beatriz. En él, Lizzie aparece con los ojos cerrados, los labios entreabiertos y el rostro levantado en un gesto de arrobamiento. Pretende ser un éxtasis místico pero la mirada masculina del artista lo recrea como un éxtasis francamente sexual, interpretación que se corrobora al comparar esta obra con el Estudio de Delia, en el que Rossetti pintó a Lizzie con este mismo gesto, pero chupando una mecha de su propio cabello mientras sostiene una especie de huso alargado en la otra mano.

El espectáculo de la mujer gozándose a sí misma la vuelve más atractiva y seductora, al tiempo que incita a una cierta violencia desatada por un instinto de posesión perverso con castigo inmediato. El hombre que desea a la mujer que yace sola en la tumba, el hombre que desea el objeto proscrito e irrecuperable, sospecha un goce secreto que lo excluye y lo orilla a la profanación. Su castigo (y quizá también su consuelo) es el espanto de hallar a la mujer transformada, convertida en pasto de gusanos, o bien en bruja con el cabello macabramente crecido. Como lo atestigua la misma Beatriz de Dante, la mujer que inspira al artista es una mujer de la cual el poeta, de alguna manera, se adueña sin su consentimiento. Los poemas de Rossetti fueron creación suya, pero la musa que lo inspiró para expresarse era también su modelo, su escultura callada posando siempre sin proferir palabra. La cabellera crecida, sin embargo, funciona como una protesta, como un reclamo estentóreo contra la injusticia de pretender anular su individualidad, reclamo que además se manifiesta en la conciencia misma del profanador como asco y repugnancia. Habla de una fuerza irreprimible que escapa a las más extremas fantasías de control, que evade a la muerte misma. Es la musa convertida en Medusa.

Y está también la línea metafórica de aquellos seres repugnantes que ahora comparten el lecho con la muerta. Los gusanos como símbolo fálico se han utilizado repetidamente en la historia de la literatura. En "To His Coy Mistress", un poema de carpe diem del siglo XVII, Andrew Marvell amenaza a la mujer diciendo 
que de no corresponderle, serán los gusanos los que usurpen su virginidad ("then worms shall try that long preserved virginity"). William Blake, en "The Sick Rose", habla de un gusano nocturno que descubre a la rosa, símbolo del sexo femenino, para destruirla con su amor oscuro y secreto ("dark secret love").

En cuanto al cabello, tiene una significación doble. Al tiempo que representa un atractivo sexual cantado hasta el cansancio por la poesía petrarquista, existe una tradición cultural paralela que lo esgrime como repelente, como protección de la castidad. El pelaje en cuentos de hadas como "Piel de Asno" y "Osita" es un refugio ante los avances ilegítimos de hombres lujuriosos. A Santa Librada, santa patrona de las novias a la fuerza, le creció la barba para escapar de una boda no deseada. Hay representaciones de la Magdalena con el cabello crecido hasta las rodillas, al grado que se le confunde con san Juan Bautista, vestido con pieles de animal. Se cuenta también que a María Magdalena y a María Egipciaca les creció el pelo milagrosamente para cubrir pudorosamente su desnudez de penitentes (Warner: 358, 360).

Sólo la fantasía de la eterna lozana, la Bella Durmiente, pareciera permitir una mirada masculina prolongada, sin la amenaza del castigo, "mirándola dormir" durante cien largos años, tiempo que le toma al "príncipe" decidirse a arriesgar la seguridad que le da su posición de Pigmalión, abriendo con el beso las puertas de la incertidumbre. Pero incluso ella ha tendido la trampa gorgónica del bosque de espinas, convertido en cementerio de pretendientes. La mujer, aun muerta, sigue perturbando sus sueños y amenazando su poder.

\section{Bibliografia}

CADALSO, José. 1984. Cartas marruecas. Noches lúgubres. Ed. Joaquín Arce. Madrid: Cátedra.

DowLING, John. "Las Noches lúgubres de Cadalso y la juventud romántica del Ochocientos". www.cervantesvirtual.com

HAWKSLEY, Linda. 2000. Essential Pre-Raphaelites. Londres: Parragon.

HENDRICKSON, Robert. 1997. Book of Literary Anecdotes. Ware, Herts.: Wordsworth.

WARNER, Marina. 1995. From the Beast to the Blonde: On Fairy Tales and Their Tellers. Cambridge: Vintage. 